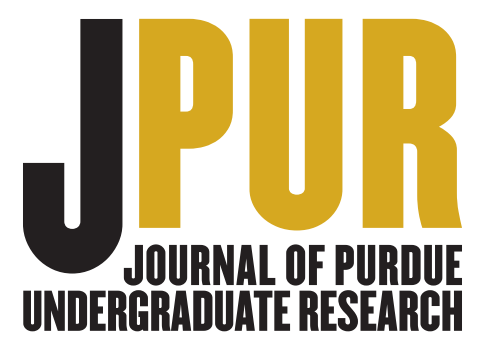

\title{
AGRICULTURE
}

\section{Tracking Life Skill Development of Indiana 4-H Members}

\section{Student researcher: Kayla Groen, Senior}

The path to adulthood has never been easy. Today's youth face challenges from family and peer expectations, social media, and rapidly changing societal norms. For more than a century, Indiana 4-H Youth Development has helped young people develop valuable life skills in problem-solving, relational maturity, and health. Periodic program assessment is crucial to ensure relevance throughout youths' progressive life stages.

Our research examined Indiana youths' self-assessments of life skills emphasized in the 4-H Targeting Life Skills Model. These skills are taught through 4-H programs in Indiana's 92 counties. The project targeted 4-H participants completing their last year of program eligibility. Data was collected in

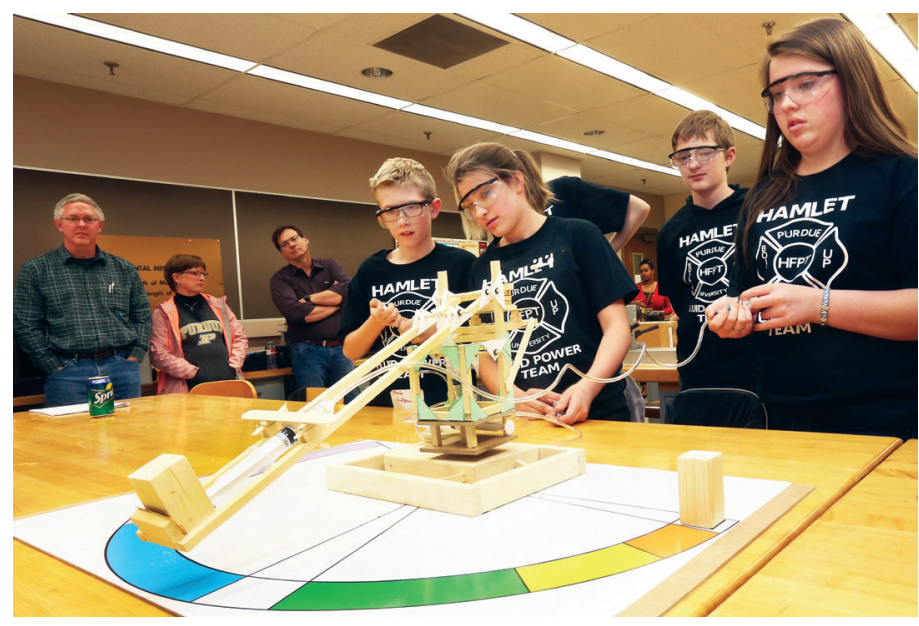

Indiana 4-H participants practice teamwork skills while learning about hydraulics at the Fluid Power Action Challenge on the Purdue University campus. early 2018 via a structured online (Qualtrics) questionnaire and mail survey methods. Participants were asked to assess the influence of 4-H on their development of 35 life skills from self-responsibility and leadership to critical thinking and stress management. Items were scaled from 1 to 5,1 being no influence and 5 being major influence.

Results ( $\mathrm{n}=653)$ indicate that $4-\mathrm{H}$ had some to moderate influence on development of all life skills assessed. Perceived influence was highest for developing communication and self-responsibility skills. Nearly three fourths of the participants rated $4-\mathrm{H}$ as having a moderate or major influence on acquisition of communication (74.4\%) and self-responsibility skills (72.4\%). Stress management (43\%) and disease prevention (40\%) were the least-rated skills assessed. Principal component analysis revealed that 4-H had the strongest perceived influence in building relating/caring skills, a key focus of the Targeting Life Skills Model. Research results will help keep Indiana 4-H programs relevant for at-risk youth in an era of declining resources.

Research advisors Renee McKee and Mark Tucker write: "Kayla's research provides a needed quantitative assessment of 4-H programs in helping prepare Indiana youth for healthy and productive adult lives in their families and communities. Equally important, the work pushes us to consider how youth development theoretical models might be re-imagined to remain relevant in tomorrow's world." 